\title{
PENGARUH TERAPI MUROTTAL TERHADAP TINGKAT NYERI PADA LANSIA YANG MENGALAMI HIPERURISEMIA (Studi di Unit Pelaksana Teknis Pelayanan Sosial Tresna Werdha Kabupaten Jombang Tahun 2017)
}

\author{
Rio Rendra Rizqi ${ }^{1}$ Hindyah Ike $S^{2}$ Ni Wayan Rahayu Ningtyas ${ }^{3}$ \\ STIKes Borneo Cendekia Medika Pangkalan Bun \\ 1email : riorendra@gmail.com, 2email : hindyahike@yahoo.com, 3email : \\ niwayanrahayu@gmail.com
}

\begin{abstract}
ABSTRAK
Nyeri sendi sering dikeluhkan oleh lansia terutama yang memiliki kadar asam urat yang tinggi. Tujuan penelitian ini adalah untuk menganalisa pengaruh terapi murottal terhadap tingkat nyeri pada lansia yang mengalami hiperurisemia di Unit Pelaksana Teknis Pelayanan Sosial Tresna Werdha Kabupaten Jombang tahun 2017. Penelitian ini berbentuk pre eksperimental dengan pendekatan one group pretest posttest. Populasi dari penelitian ini sebanyak 53 lansia dengan jumlah responden sebanyak 47 lansia, teknik pengambilan sampel adalah simple random sampling. Variabel independen dari penelitian ini adalah terapi murottal dan variabel dependen adalah tingkat nyeri pada lansia yang mengalami hiperurisemia. Alat ukur yang digunakan adalah VAS (Visual Analog Scale) dan lembar observasi, kemudian pengolahan data dimulai dari editing, coding, scoring, dan tabulating. Analisa data yang digunakan adalah uji Wilcoxon $(\alpha=0,05)$. Hasil penelitian didapatkan, tingkat nyeri sebelum terapi murottal diperoleh bahwa sebagian lansia mengeluhkan nyeri ringan $(10,6 \%)$, hampir seluruhnya mengeluhkan nyeri sedang $(61,7 \%)$ dan sebagian lagi mengalami nyeri berat $(27,7 \%)$. Tingkat nyeri sesudah terapi murottal diperoleh bahwa sebagian lansia mengeluhkan nyeri ringan $(61,7 \%)$ dan sebagian lagi mengeluhkan nyeri sedang $(38,3 \%)$. Hasil uji Wilcoxon menunjukkan $\mathrm{p}=0,000$ yang menunjukkan bahwa $\mathrm{p}<0,05$. Kesimpulan dari penelitian ini adalah ada pengaruh terapi murottal terhadap tingkat nyeri pada lansia yang mengalami hiperurisemia.
\end{abstract}

Kata kunci: hiperurisemia, nyeri, terapi murottal.

\section{INFLUENCE OF MUROTTAL THERAPY ON THE LEVEL OF PAIN IN THE ELDERLY WHO EXPERIENCED HYPERURICEMIA (Study at Technical Implementation Unit of Tresna Werdha Social Service of Jombang Regency 2017)}

\begin{abstract}
Joint pain is often complained by the elderly, especially those who have a high uric acid levels. The point of this research was to analyze the influence of murottal therapy on the level of pain in the elderly who experienced hyperuricemia in Technical Service Unit of Social Tresna Werdha Jombang Regency in 2017. The design of this study was pre experimental with one group pretest posttest approach. The population of this study as many as 53 elderly with the number of respondents as many as 47 elderly, sampling technique is simple random sampling. Independent variable of this research is murottal therapy and dependent variable is level of pain
\end{abstract}


in elderly who have hyperuricemia. The measuring tools used are VAS (Visual Analog Scale) and observation sheet, then data processing starts from editing, coding, scoring, and tabulating. The data analysis used is Wilcoxon test $(\alpha=0,05)$. The results of the study showed that the pain level before murottal therapy showed that some of the elderly had mild pain (10.6\%), almost all had moderate pain (61.7\%) and some had severe pain (27.7\%). Pain level after murottal therapy was obtained that some elderly had mild pain (61.7\%) and others had moderate pain (38.3\%). Wilcoxon test results show $p=0.000$ indicating that $p<0.05$. The conclusion of this research is the influence of murottal therapy on the level of pain in elderly who have hyperuricemia.

Keywords: hyperuricemia, pain, murottal therapy.

\section{PENDAHULUAN}

Asam urat pasti terdapat disetiap tubuh manusia, karena setiap metabolisme normal akan dihasilkan asam urat (Ariani, 2016, 12). Kadar asam urat yang diproduksi tubuh tentunya dengan jumlah yang masih dalam batas normal, akan tetapi kadar asam urat ini juga dapat berlebih atau dikenal dengan istilah hiperurisemia. Keadaan ini jika dibiarkan terus-menerus nantinya dapat menyebabkan berbagai masalah dipersendian. Nyeri ini dihasilkan oleh proses peradangan yang terjadi pada sendi. Nyeri dapat terjadi satu atau beberapa sendi dan akan bertambah buruk terutama pada malam hari. Kulit diatas sendi yang mengalami radang, jika terkena sentuhan akan menimbulkan nyeri yang sangat hebat (Ariani, 2016, 13). Lansia juga tidak luput dari serangan asam urat ini, terkadang para lansia mengeluhkan nyeri di persendiannya sehingga tidak dapat melakukan aktivitas bahkan untuk berdiripun susah, mereka hanya duduk atau berbaring sambil menunggu nyeri yang dialami hilang dengan sendirinya.

Wortman dan Poor G. (2009) penderita hiperurisemia sekitar 2,6-47,2 \% dari populasi dunia (Hasanah, 2015, 50).
World Health Organization menyebutkan Indonesia memasuki urutan ke 4 negara dengan penderita asam urat atau hiperurisemia (Oktaviani, 2016, 2). Di Indonesia jumlah penderita hiperurisemia menduduki urutan kedua setelah osteoarthritis dengan prevalensi penduduk yang menderita penyakit asam urat sekitar 1,6-13,6 dari 100.000 orang (Purnamasari dan Anita, 2015, 20). Survey yang dilakukan di Jawa Tengah melalui kerjasama WHOCOPCORD terhadap 4.683 sampel, didapatkan hasil yaitu secara keseluruhan penderita hiperurisemia untuk kedua kelamin adalah 17,6\% (Dianati, 2015 didalam Hidayah, 2017, 2). Data penderita radang sendi yang diakibatkan hiperurisemia sebanyak 244 orang. Studi pendahuluan di posyandu Dahlia dusun Ngemplak desa Ngudirejo, Jombang didapatkan 10 lansia yang menderita hiperurisemia mengeluhkan nyeri pada persendiannya. Dari 10 orang tersebut didapati ada 7 lansia yang mengeluhkan nyeri berat.

Asam urat merupakan limbah, sebagian besar asam urat akan dibuang dalam bentuk urin, jika kadar asam urat yang dibuang melalui tubuh lebih sedikit dibandingkan yang diproduksi, maka 
dapat menyebabkan peningkatan kadar asam urat didalam darah atau dikenal dengan istilah hiperurisemia (Wati, 2017, 2). Peningkatan kadar asam urat ini jika dibiarkan terus-menerus nantinya dapat menyebabkan berbagai masalah kesehatan seperti peradangan pada persendian. Peradangan pada sendi diakibatkan oleh penumpukan asam urat yang membentuk kristalkristal tajam dan masuk kedalam ruang sendi serta merusak lapisan lunak sendi (Ariani, 2016, 13). Kristal-kristal yang menumpuk dan mengendap jika dibiarkan terus-menerus, lamakelamaan dapat mengubah bentuk sendi dan mengakibatkan kecacatan sendi (Akmal et all, 2016, 35).

Upaya untuk mengurangi tingkat nyeri yang disebabkan oleh tingginya kadar asam urat pada lansia bisa dilakukan dengan upaya nonfarmakologi yaitu, mendengarkkan murottal. Terapi murotal merupakan suatu cara untuk mempercepat penyembuhan, hal ini dibuktikan oleh penelitian Ahmad Al Khadi dari Islamic Medicine Institute for Education and Research di Florida, Amerika Serikat. Hasil penelitian yang didapatkan bahwa mendengarkan ayat suci Al Quran memiliki pengaruh yang baik dalam mengurangi ketegangan saraf (Yolanda dan Yunita, 2015, 7). Terapi murottal ini didengarkan melalui tape recorder atau Mp3 player dan ayat- ayat yang digunakan yaitu terdiri dari surat pendek karena mudah dan sudah biasa didengar. Durasi yang diberikan kurang lebih selama 15 menit, hal ini sejalan dengan penelitian yang dilakukan Yolanda dan Yunita $(2015,7)$ yaitu pemberian terapi musik atau suara selama 10-15 menit sudah dapat memberikan efek menenangkan atau relaksasi. Berdasarkan uraian di atas mengenai nyeri yang timbul pada penderita asam urat, maka diperlukan pengkajian lebih mendalam sehingga peneliti tertarik untuk meneliti mengenai pengaruh terapi murottal terhadap tingkat nyeri pada lansia yang menderita hiperurisemia.

\section{METODE PENELITIAN}

Jenis penelitian ini adalah pre eksperimental dengan desain one group pretest post test (Kasiran, didalam Sujarweni, 2014, 179). Populasi pada penelitian ini adalah lansia yang mengalami nyeri hiperurisemia sebanyak 53 lansia yang mengalami hiperurisemia di UPT PSTW Kabupaten Jombang. Simple random sampling digunakan sebagai teknik sampling dengan jumlah sampel 47 responden. Variabel Independen penelitian ini adalah terapi murottal dan variabel dependen adalah tingkat nyeri pada lansia yang mengalami hiperurisemia. Alat pengumpulan data berupa lembar observasi dan Visual Analog Scale (VAS). Lembar observasi berisikan data umum (Usia, Jenis Kelamin, Tingkat pendidikan, olahraga dan lokasi nyeri).

\section{HASIL PENELITIAN}

Tabel 1 Distribusi frekuensi berdasarkan umur lansia di UPT PSTW Kabupaten Jombang 2017

\begin{tabular}{ccc}
\hline Umur (tahun) & $\mathrm{N}$ & $\%$ \\
\hline $63-66$ & 4 & 10,4 \\
$67-69$ & 8 & 16,7 \\
$70-74$ & 17 & 35,4 \\
$75-79$ & 12 & 25,0 \\
$80-83$ & 4 & 8,3 \\
$85-86$ & 2 & 4,2 \\
\hline Jumlah & 47 & 100 \\
\hline \multicolumn{2}{l}{ Sumber: Data primer 2017} &
\end{tabular}


Tabel 1 menunjukkan bahwa hampir setengahnya lansia memiliki umur 7074 tahun sebanyak 17 lansia $(35,4 \%)$.

Tabel 2 Distribusi frekuensi berdasarkan jenis kelamin lansia di UPT PSTW Kabupaten Jombang 2017

\begin{tabular}{ccc}
\hline Jenis Kelamin & $\mathrm{N}$ & $\%$ \\
\hline Laki-laki & 13 & 27,7 \\
Perempuan & 34 & 72,3 \\
\hline Jumlah & 47 & 100 \\
\hline Sumber: Data primer 2017 &
\end{tabular}

Tabel 2 menunjukkan bahwa sebagian besar lansia berjenis kelamin perempuan sebanyak 34 lansia $(72,3 \%)$.

Tabel 3 Distribusi frekuensi berdasarkan tingkat pendidikan lansia di UPT PSTW Kabupaten Jombang 2017

\begin{tabular}{ccc}
\hline Tingkat Pendidikan & $\mathrm{N}$ & $\%$ \\
\hline Tidak sekolah & 10 & 21,3 \\
Tidak tamat sekolah & 1 & 2,1 \\
Sekolah dasar (SD) & 24 & 51,1 \\
Sekolah menengah & 12 & 25,5 \\
pertama (SMP) & & \\
Sekolah menengah atas & 0 & 0 \\
(SMA) & 0 & 0 \\
Perguruan tinggi & 0 & 100 \\
\hline Jumlah & 47 &
\end{tabular}

Tabel 3 menunjukkan bahwa sebagian besar lansia yang memiliki tingkat pendidikan sekolah dasar (SD) sebanyak 24 lansia $(51,1 \%)$.

Tabel 4 Distribusi frekuensi berdasarkan olahraga di UPT PSTW Kabupaten Jombang 2017

\begin{tabular}{ccc}
\hline Olahraga & $\mathrm{N}$ & $\%$ \\
\hline Rutin & 47 & 100 \\
Tidak rutin & 0 & 0 \\
\hline Jumlah & 47 & 100 \\
\hline Sumber: Data primer 2017
\end{tabular}

Tabel 4 menunjukkan bahwa seluruh lansia melakukan olahraga secara rutin sebanyak 47 lansia (100\%).

Tabel 5 Distribusi frekuensi berdasarkan lokasi nyeri lansia di UPT PSTW Kabupaten Jombang 2017

\begin{tabular}{ccc}
\hline Lokasi nyeri & $\mathrm{N}$ & $\%$ \\
\hline Tangan & 1 & 2,1 \\
Lutut & 21 & 44,7 \\
Kaki & 25 & 53,2 \\
\hline Jumlah & 47 & 100 \\
\hline \multicolumn{2}{l}{ Sumber: Data primer 2017} &
\end{tabular}

Tabel 5 menunjukkan bahwa sebagian besar lansia mengeluhkan nyeri di kaki sebanyak 25 lansia $(53,2 \%)$.

Tabel 6 Distribusi frekuensi berdasarkan tingkat nyeri sebelum (pre test) pemberian terapi murottal di UPT PSTW Kabupaten Jombang 2017

\begin{tabular}{ccc}
\hline Tingkat nyeri (pre test) & $\mathrm{N}$ & $\%$ \\
\hline Tidak nyeri & 0 & 0 \\
Nyeri ringan & 5 & 10,6 \\
Nyeri sedang & 29 & 61,7 \\
Nyeri berat & 13 & 27,7 \\
Nyeri yang tidak & 0 & 0 \\
tertahankan & & \\
\hline Jumlah & 47 & 100 \\
\hline Sumber: Data primer 2017 & &
\end{tabular}

Tabel 6 menunjukkan bahwa tingkat nyeri sebelum pemberian terapi murottal (pretest), sebagian besar lansia mengeluhkan nyeri sedang sebanyak 29 lansia $(61,7 \%)$.

Tabel 7 Distribusi frekuensi berdasarkan tingkat nyeri sesudah (post test) pemberian terapi murottal di UPT PSTW Kabupaten Jombang 2017 


\begin{tabular}{ccc}
\hline Tingkat nyeri & $\mathrm{N}$ & $\%$ \\
sesudah (post test) & & 0 \\
\hline Tidak nyeri & 0 & 61,7 \\
Nyeri ringan & 29 & 61,7 \\
Nyeri sedang & 18 & 38,3 \\
Nyeri berat & 0 & 0 \\
Nyeri yang tidak & 0 & 0 \\
tertahankan & & 100 \\
\hline Jumlah & 47 &
\end{tabular}

Tabel 7 menunjukkan bahwa tingkat nyeri sesudah pemberian terapi murottal (post test), sebagian besar lansia mengeluhkan nyeri ringan sebanyak 29 lansia $(61,7 \%)$.

Tabel 8 Pengaruh terapi murottal terhadap tingkat nyeri pada lansia yang mengalami hiperurisemia di UPT PSTW Kabupaten Jombang 2017

\begin{tabular}{ccccc}
\hline \multirow{2}{*}{ Tingkat nyeri } & \multicolumn{2}{c}{ Pretest } & \multicolumn{2}{c}{ Post test } \\
\cline { 2 - 5 } & $\mathrm{N}$ & $\%$ & $\mathrm{~N}$ & $\%$ \\
\hline Tidak nyeri & 0 & 0 & 0 & 0 \\
Nyeri ringan & 5 & 10,6 & 29 & 61,7 \\
Nyeri sedang & 29 & 61,7 & 18 & 38,3 \\
Nyeri berat & 13 & 27,7 & 0 & 0 \\
Nyeri yang tidak & 0 & 0 & 0 & 0 \\
tertahankan & & & \\
\hline Jumlah & 47 & 100 & 47 & 100 \\
\hline Uji wilcoxon & $\mathrm{p}=0.000$ & \\
\hline
\end{tabular}

Berdasarkan hasil analisis menggunakan SPSS 16, didapatkan hasil uji wilcoxon adalah 0,000 , hal ini menunjukkan nilai $\mathrm{p}<0,05$ maka $\mathrm{H} 1$ diterima dan $\mathrm{H} 0$ di tolak, atau dengan kata lain ada pengaruh terapi murottal Al Quran terhadap tingkat nyeri pada lansia yang mengalami hiperurisemia di Unit Pelaksana Teknis Pelayanan Sosial Tresna Werdha Kabupaten Jombang tahun 2017.

\section{PEMBAHASAN}

Tingkat nyeri sebelum pemberian terapi murottal Al Quran
Tabel 6 menunjukkan bahwa tingkat nyeri sebelum pemberian terapi murottal (pretest), sebagian besar lansia mengeluhkan nyeri sedang sebanyak 29 lansia $(61,7 \%)$.

Peneliti berasumsi tingkat nyeri yang dialami lansia dapat dipengaruhi beberapa faktor yaitu, usia, jenis kelamin, pendidikan, dan olahraga. Semakin tua atau semakin bertambah usia seseorang dapat membuat tingkat nyeri semakin tidak jelas karena berbagai penyakit yang dialami juga bertambah. Hiperurisemia biasa menyerang pada pria diatas 30 tahun dan wanita yang sudah menopause. Olahraga juga dapat melemaskan dan menghangatkan suhu tubuh terutama pada daerah atau sendi perifer. Zakiyah (2015, 22) menyebutkan bahwa usia, jenis kelamin, perhatian, makna nyeri, ansietas, mekanisme koping, keletihan, pengalaman sebelumnya, dukungan keluarga dan sosial, dapat menjadi faktor yang bisa mempengaruhi tingkat nyeri.

\section{Tingkat nyeri sesudah pemberian terapi murottal Al Quran}

Tabel 7 menunjukkan tingkat nyeri sesudah terapi murottal (post test), sebagian besar lansia mengeluhkan nyeri ringan sebanyak 29 lansia $(61,7 \%)$.

Peneliti berasumsi bahwa tingkat nyeri dapat berkurang karena terdapat faktor relaksasi. Saat mendengarkan bacaan Al Quran yang dilagukan dengan baik maka akan menimbulkan rasa nyaman dan tenang.

Hal ini sejalan dengan penelitian Yolanda dan Yunita $(2015,7)$ yaitu terapi murottal dapat membuat 
perasaan menjadi tenang atau rileks, mengalihkan perhatian dari rasa tegang, takut, cemas, dan perbaikan sistem kimia tubuh yang dapat menurunkan tekanan darah serta dapat menurunkan aktivitas gelombang otak, memperlambat pernafasan, detak jantung, denyut nadi. Pernafasan yang lebih lambat dan dalam sangat baik untuk menimbulkan perasaan tenang, pengendalian emosi yang lebih baik, pemikiran yang lebih dalam dan metabolisme tubuh akan menjadi lebih baik. Alkahel 2011 dikutip dari (Handayani et all, 2012, 127), juga menyebutkan bahwa bacaan Al Quran yang dilagukan dengan baik memiliki efek relaksasi yang cukup besar yaitu 65\%. Terapi murottal dapat mengaktifkan sel-sel tubuh dengan menjadikan suara menjadi gelombang yang diterima tubuh, menurunkan respon reseptor nyeri dan otak akan mengeluarkan penghilang nyeri opioid natural endogen. Opioid ini bekerja dengan cara menghambat nosiseptor nyeri.

\section{Pengaruh terapi murottal terhadap tingkat nyeri pada lansia yang mengalami hiperurisemia}

Tabel 8 menunjukkan, hasil analisis uji wilcoxon menggunakan SPSS 16 adalah 0,000. Hasil analisis statistik yang dilakukan menggunakan uji Wilcoxon dimana $p=0,000$ maka $p=<$ 0,05 yang artinya hipotesis peneliti terbukti bahwa terdapat pengaruh terapi murottal terhadap tingkat nyeri pada lansia yang mengalami hiperurisemia di Unit Pelaksana Teknis Pelayanan Sosial Tresna Werdha Kabupaten Jombang tahun 2017. Data yang diperoleh dari 47 responden setelah dilakukan terapi murottal sebanyak 3 kali selama 15 menit menunjukkan bahwa responden dengan skala nyeri berat turun menjadi nyeri sedang sebanyak 8 orang, responden dengan skala nyeri berat turun menjadi nyeri ringan sebanyak 1 orang, responden dengan skala nyeri sedang yang turun menjadi nyeri ringan sebanyak 16 orang, dan terdapat 22 orang yang merasakan nyeri dengan skala yang sama tetapi dengan penurunan 1-2 skala angka.

Peneliti berpendapat terapi murottal memiliki pengaruh terhadap tingkat nyeri pada lansia yang mengalami hiperurisemia. Lansia mengatakan terjadi penurunan intensitas nyeri yang dialami setelah dilakukan terapi murottal sebanyak 3 kali selama 15 menit. Mereka yang didengarkan murottal dengan irama dan bacaan yang baik akan merasa tenang dan rileks. Hal ini dikarenakan saat seseorang didengarkan bacaan $\mathrm{Al}$ Quran akan menstimulasi otak untuk menghasilkan hormon yang berperan sebagai penurun nyeri alami yaitu beta endorphin. Selain itu juga dapat menghambat produksi hormon yang dapat menjadi pemicu nyeri yang semakin hebat seperti hormon kortisol.

Saat seseorang menerima stimulus berupa irama murottal Al-Quran yang konstan, teratur dan tidak memiliki perubahan irama yang mendadak terjadi proses adaptasi kognator (persepsi, informasi, emosi) dan regulator (kimiawi, saraf, endokrin) yang mempengaruhi cerebral cortex dalam aspek kognitif maupun emosi sehingga menghasilkan persepsi positif dan peningkatan relaksasi hingga $65 \%$ yang secara tidak langsung menjaga keseimbangan homeostasis tubuh melalui HPA Axis (sistem neuroendokrin hipotalamus yang mengatur relaksasi stress) untuk menghasilkan Citicitropin Relasing 
Factor (CRF) yang berfungsi merangsang kelenjar pituitari untuk menurunkan produksi ACTH (Adreno Cortico Tropin Hormone) yang menstimulasi produksi endorphine, khususnya $\beta$-endorphine yang memiliki efek natural analgesik dan kemudian menurunkan produksi kortisol dan hormon-hormon stress lainnya sehingga nyeri menurun (Alkahel, 2011 dalam Khashinah, 2015, 6-7).

\section{KESIMPULAN DAN SARAN}

\section{Kesimpulan}

1. Tingkat nyeri sebelum terapi murottal (pretest) yaitu sebagian besar lansia mengalami nyeri sedang sebanyak 29 lansia.

2. Tingkat nyeri sesudah terapi murottal (post test) yaitu sebagian besar lansia mengalami nyeri ringan sebanyak 29 lansia.

3. Ada pengaruh terapi murottal terhadap tingkat nyeri pada lansia yang mengalami hiperurisemia di Unit Pelaksana Teknis Pelayanan Sosial Tresna Werdha Kabupaten Jombang tahun 2017.

\section{Saran}

1. Bagi lansia

Penelitian ini dapat dijadikan tindakan alternatif dalam mengurangi tingkat nyeri yang dialami oleh lansia selain menggunakan obat-obatan penghilang rasa nyeri.

2. Petugas kesehatan panti

Penelitian ini dapat dijadikan salah satu intervensi nonfarmakologis selain kompres hangat maupun dingin dalam mengurangi nyeri pada lansia yang mengalami hiperurisemia.

3. Peneliti selanjutnya
Diharapkan peneliti selanjutnya dapat menjadikan penelitian ini sebagai rujukan dan sumber informasi serta dapat membandingkan efektifitas berbagai bentuk terapi nonfarmakologis seperti terapi musik dan audio lainnya dalam mengurangi nyeri.

\section{DAFTAR PUSTAKA}

Akmal, Mutaroh, et all. 2016. "Ensiklopedi Kesehatan". Yogyakarta: Ar-ruzz Media.

Ariani, dr. Sofi. 2016. "Stop Gagal Ginjal dan Gangguan-gangguan Ginjal Lainnya”. Yogyakarta: Inti Media.

Handayani, et all. 2012. "Pengaruh Terapi Murottal Al Quran untuk Penurunan Nyeri Persalinan dan Kecemasan pada Ibu Bersalin Kala 1 Fase Aktif'. Jurnal Ilmiah Kebidanan, Vol. 5 No. 2, hal. 115

Hasanah, Neng Lilis Nur. 2015. "Perbandingan antara Pemberian Allopurinol dan Air Rebusan Jeruk Nipis (Citrus Aurantifolia) terhadap Penurunan Kadar Asam Urat pada Mencit Model Hiperurisemia".Universitas Islam. Bandung.

Hidayah, Nurul. 2017. "Hubungan Hiperurisemia pada Saat Masuk Rumah Sakit dengan Defisit Neurologis pada Kejadian Stroke Iskemik". Surakarta: Universitas Muhammadiyah Surakarta.

Khashinah, Nurul. 2015. "Pengaruh Terapi Murottal Juz'Amma terhadap Tingkat Nyeri pada Pasien Post Open Reduction 
Internal Fixation (Orif)". STIKes Aisyiyah. Yogyakarta.

Oktaviani, Ira Maya. 2016. "Pengaruh Rebusan Daun Pacar Kuku (Lawsonia Inermis Linn.) terhadap Penurunan Kadar Asam Urat Darah Mencit Jantan BALB-C (Mus Musculus L.) dan Pemanfaatannya sebagai Karya Ilmiah Populer". Digital Repository Universitas Jember diakses dalam http://repository.unej.ac.id/handle /123456789/79730/ira (diakses pada tanggal 16 april 2017). pukul 15.45 WIB.

Wati, Intan Prasetyo. 2017. "Upaya Pendidikan Kesehatan untuk Mengurangi Resiko Hiperurisemia pada Ny. $R$ dengan Gout Di Desa Luwang". UniversitasMuhammad iyah Surakarta. Di dalam http://eprints.ums.ac.id/52375/

(Diakses pada tanggal 16 April 2017). Pukul 15.23 WIB.

Purnamasari, S.D.I. dan Anita Dyah Listyarini. 2015. "Kompres Air Rendaman Jahe dapat Menurunkan Nyeri pada Lansia dengan Asam Urat di Desa Cengkalsewu Kecamatan Sukolilo Kabupaten Pati”. STIKes Cendekia Utama. Kudus.

Sujarweni, V. Wiratna. 2014. "Metodologi Penelitian Keperawatan”. Yogyakarta: Gava Media.

Yolanda, Debby dan Yunita Widyanti. 2015. “ Pengaruh Terapi Murottal Terhadap Penurunan Nyeri Persalinan pada Primigravida". STIkes Yarsi Sumbar. Bukittinggi.
Zakiyah, Ana. 2015. "Nyeri : Konsep dan Penatalaksanaan dalam Praktik Keperawatan Berbasis Bukti”. Jakarta: Salemba Medika. 